\title{
PENGGUNAAN SENSOR FOTODETEKTOR UNTUK PENGUKURAN KANDUNGAN GULA DI DALAM LARUTAN NIRA TEBU
}

\author{
Application of Photodetector Sensor for Sugar Content Measurement in \\ Sugar Cane Juice
}

\author{
Alex Taufiqurrohman Zain ${ }^{1 \star}$, Cahyaning Nur Karimah ${ }^{1}$, Mochamad Irwan Nari ${ }^{1}$, dan \\ Anni Nuraisyah ${ }^{2}$ \\ 1 Jurusan Teknik Politeknik Negeri Jember \\ Jl. Mastrip No. 164, Jember 68124 \\ 2 Jurusan Produksi Pertanian Politeknik Negeri Jember \\ JI. Mastrip No. 164, Jember 68124 \\ e-mail: Alextaufiqurrohman@polije.ac.id
}

\begin{abstract}
Cane is one of the sugar-producing plants. The quality of produced sugar is greatly influenced by main raw material, cane juice, so sugar content measurement in sugar cane is needed. In this study, measuring sugar content in cane juice is integrated with a PC system. In addition to cane juice, sugar solutions are used as an object in this study. Measuring devices are made using light propagation principle when passing through the object. The light source used is RGB bright $L E D$, fiber optic as a propagation medium of ray, photodiode BPW 34 as a photodetector, Arduino UNO module as a microcontroller module, and digital refractometer to obtain comparable data. The results showed that the measuring instrument could be integrated with a PC system. Research on sugar solution shows that yellow light is able to provide the greatest change in the output of sensor system for each variation of solution concentration, and a calibration curve is obtained for further study on cane juice. Research on cane juice shows that there are still differences in the results of sugar content measurement from photodetectors to digital refractometers.
\end{abstract}

Keywords: photodiode, calibration curve, sugar cane juice

\begin{abstract}
Abstrak: Tebu merupakan salah satu tanaman penghasil gula. Kualitas gula yang dihasilkan sangat dipengaruhi oleh bahan baku utamanya yaitu nira tebu, sehingga diperlukan pengukuran kandungan nira pada tebu. Pada penelitian ini, dibuat alat ukur kandungan gula pada nira tebu yang terintegrasi dengan sistem PC. Selain nira tebu, digunakan larutan gula sebagai objek penelitian lainnya. Alat ukur yang dibuat memanfaatkan prinsip penjalaran sinar ketika melewati objek penelitian. Sumber sinar yang digunakan adalah RGB bright LED, fiber optic sebagai medium perambatan sinar, fotodioda BPW 34 sebagai fotodetektor, modul Arduino UNO sebagai modul mikrokontroler, dan refraktometer digital untuk mendapatkan data pembanding. Hasil penelitian menunjukkan bahwa alat ukur sudah bisa terintegrasi dengan sistem PC. Penelitian pada larutan gula menunjukkan bahwa sinar kuning mampu memberikan perubahan tegangan keluaran sistem sensor yang paling besar setiap variasi konsentrasi larutan, dan didapatkan kurva kalibrasi untuk penelitian pada nira tebu selanjutnya. Penelitian pada nira tebu menunjukkan bahwa masih ada perbedaan hasil pengukuran kandungan gula dari fotodetektor terhadap refraktometer digital.
\end{abstract}

Kata kunci: fotodioda, kurva kalibrasi, nira tebu.

\section{PENDAHULUAN}

Kemajuan teknologi membawa dampak pada kemampuan industri elektronika memproduksi peralatan yang mampu menunjang aktivitas dan kreativitas manusia (Priambodo, 2013). Bidang instrumentasi optik merupakan salah satu bidang yang saat ini mengalami kemajuan teknologi.
Perangkat instrumentasi optik terdiri dari sumber sinar, media transmisi, dan sensor penerima yang digunakan untuk mengukur besaran fisis dari suatu bahan. Serat optik merupakan media transmisi sinar dari laser atau Light Emitting Diode (LED) menuju fotodetektor. Selain untuk transmisi data, serat optik juga dapat digunakan sebagai sensor. Pemanfaatan 
serat optik sebagai sensor dapat digunakan pada pengukuran kadar gula, biomedis, dan farmasi (Fajarini, 2011). Penelitian kadar glukosa dalam air distilasi menggunakan serat optik berbasis sensor pergeseran dengan probe bundel menunjukkan bahwa puncak tegangan atau intensitas sinar sebanding dengan konsentrasi glukosa. Sejalan dengan penelitian tersebut, pengujian kadar glukosa dalam air distilasi menggunakan serat optik berbasis sensor pergeseran dengan fiber coupler menunjukan bahwa semakin tinggi konsentrasi larutan glukosa yang digunakan, semakin tinggi pula tegangan keluaran yang dihasilkan (Aini et al., 2013). Penelitian serupa juga telah dilakukan oleh Binu et al. (2009). Penelitian tersebut menggunakan prinsip penjalaran sinar yang ditransmisikan oleh serat optik. Selanjutnya, sinar akan melalui larutan glukosa dengan variasi konsentrasi. Adanya permukaan refleksi akan berpengaruh terhadap intensitas sinar yang diterima oleh fotodetektor berdasarkan indeks bias sinar. Sinar yang diterima oleh fotodetektor akan diubah menjadi besaran listrik berupa tegangan. Berdasarkan penelitian tersebut, semakin tinggi konsentrasi larutan glukosa, maka indeks bias sinar akan semakin besar pula. Hasil lain menunjukkan bahwa tegangan keluaran yang terukur oleh multimeter digital akan naik secara linear ketika terdapat perubahan konsentrasi larutan gula.

Pada penelitian ini, dibuat alat ukur kandungan gula pada nira tebu. Alat yang dibuat memanfaatkan sensor cahaya berupa PIN fotodioda, Light Emitting Diode (LED) yang digunakan sebagai sumber cahaya, serat optik yang digunakan sebagai media transmisi dari sumber sinar, dan modul Arduino UNO yang digunakan sebagai modul mikrokontroler yang dihubungkan dengan PC. Prinsip alat ini adalah sinar dilewatkan melalui serat optik. Selanjutnya, paket-paket energi dari sinar akan diteruskan ke sampel nira tebu oleh serat optik. Karena sifat optik dari larutan yang berwarna agak keruh maka akan ada sinar yang diserap oleh larutan. Serat optik yang digunakan adalah single mode fiberoptic. Hal ini disebabkan oleh penggunaan LED sebagai sumber sinar serta fotodioda sebagai fotodetektor. Selain itu, transmisi yang dihasilkan semakin tinggi dengan ukuran diameter yang kecil (Waluyo dan Agus, 2009). Pemilihan fotodioda sebagai fotodetektor adalah didasarkan pada tingkat kepekaannya yang sangat baik terhadap setiap perubahan intensitas sinar yang mengenainya jika dibandingkan dengan jenis fotodetektor lainnya (Sary, 2009). Penelitian ini diharapkan mampu memberikan pilihan lain untuk alat ukur kandungan gula yang tentunya sudah terkalibrasi oleh alat ukur konvensional yang selama ini digunakan yaitu refraktometer. Penelitian ini menggunakan dua spektrum sinar, yaitu sinar kuning dan sinar ungu yang selanjutnya akan dipilih spektrum warna apa yang lebih baik digunakan untuk mengukur kandungan gula pada nira tebu.

\section{METODOLOGI}

Alat yang dibuat menggunakan RGB bright LED sebagai sumber sinar, fiber optic sebagai medium perambatan sinar, fotodioda BPW 34 sebagai fotodetektor, modul Arduino UNO sebagai modul mikrokontroler, sedangkan software pemrograman yang digunakan adalah LabVIEW 201264 bit, LabVIEW interface for Arduino, serta Arduino IDE 1.0.4. Untuk mendapatkan data pembanding maka digunakan refraktometer digital.

Bahan awal yang digunakan adalah sampel larutan gula dengan 10 variasi konsentrasi yaitu 0 gram/liter, 25 gram/liter, 50 gram/liter, 75 gram/liter, 100 gram/liter, 125 gram/liter, 150 gram/liter, 175 gram/liter, 200 gram/liter, dan 225 gram/liter serta 12 sampel nira tebu. Nira tebu didapatkan dari empat batang tebu yang masing-masing batangnya dibagi menjadi tiga bagian ruas, yaitu ruas atas, ruas tengah, dan ruas bawah dengan rentang $\mathrm{pH}$ sebesar 4,5-5,7 (Zain et al., 2020).

Penelitian ini memanfaatkan 
prinsip penjalaran (transmisi) sinar ketika sumber sinar (sinar RGB bright LED) masuk melalui serat optik, kemudian diteruskan melewati objek penelitian. Setelah melewati objek penelitian, sinar akan diteruskan melalui serat optik kembali dan ditangkap oleh PIN fotodioda (BPW 34) sebagai sinyal gelombang input. Besarnya intensitas sinar LED yang diterima akan dikonversi menjadi bentuk tegangan oleh PIN fotodioda. Karena adanya efek atenuasi maka intensitas sinar LED yang diterima oleh PIN fotodioda akan berkurang sehingga perlu adanya rangkaian penguat operasional untuk mendapatkan tegangan yang mampu terbaca oleh alat ukur (Zain et al., 2020). Adapun desain rangkaian alat pada penelitian ini adalah sebagai berikut.

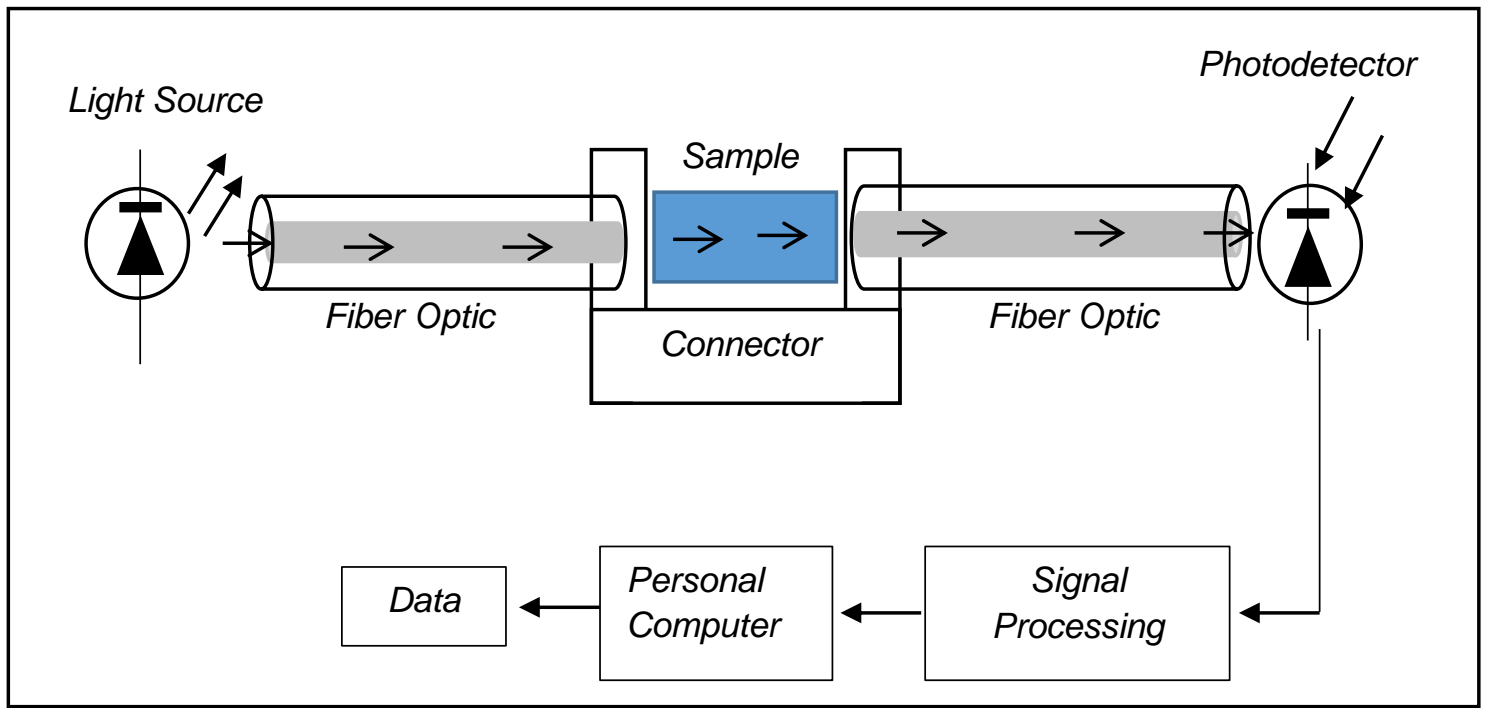

Gambar 1. Desain Rangkaian Alat Ukur (Zain et al., 2020)

Adapun tegangan output rangkaian Op Amp yang terukur akan ditampilkan pada PC. Selain itu, warna sinar yang dipancarkan oleh RGB bright LED juga mampu dikendalikan melalui PC. Agar dapat melakukan hal tersebut maka diperlukan script pemrograman yang selanjutnya diunggah ke modul Arduino UNO melalui Arduino IDE 1.0.4. Arduino IDE 1.0.4 merupakan software dasar yang digunakan untuk menulis dan mengunggah script pemrograman ke modul Arduino UNO. Arduino tersusun dari dua bagian utama yaitu Arduino board dan Arduino IDE (Integrated Development Environment). Arduino board berupa hardware yang digunakan ketika menyusun rangkaian. Sedangkan Arduino IDE merupakan software yang digunakan untuk pengolahan pada PC. Arduino IDE digunakan untuk membuat gambaran program komputer yang diunggah ke Arduino board. Gambaran program digunakan untuk menentukan pekerjaan yang harus dilakukan oleh Arduino board (Banzi, 2011).

Perintah pada modul Arduino UNO dapat dilakukan dengan lebih mudah. Modul Arduino UNO dapat dikendalikan dengan software LabVIEW 2012 seri 64 bit. Hal ini dapat dilakukan dengan mengintegrasikan antara Arduino IDE 1.0.4 dengan LabVIEW 201. LabVIEW menggunakan pemrograman aliran data (dataflow) yang akan menentukan perintah eksekusi berdasarkan VI. VI atau Virtual Instrument adalah program LabVIEW yang menirukan instrumen sebenarnya dalam bentuk simbol-simbol (Pratama et al., 2011). Setelah integrasi berhasil, maka perintah dari modul Arduino UNO tidak lagi menggunakan script mirip bahasa $\mathrm{C} / \mathrm{C}++$ namun menggunakan blok-blok program dataflow. Adapun spesifikasi dari modul Arduino UNO yang digunakan ditampilkan pada Tabel 1. 
Tabel 1. Spesifikasi Modul Arduino UNO

\begin{tabular}{lc}
\hline \multicolumn{1}{c}{ Komponen } & Spesifikasi \\
\hline Microcontroler & ATMega328 \\
Operation Voltage & $5 \mathrm{~V}$ \\
Input Voltage & $7 \mathrm{~V}-12 \mathrm{~V}$ (rekomendasi) \\
Input Voltage & $6 \mathrm{~V}-20 \mathrm{~V}$ (limit) \\
I/O & 14 pin (6 pin untuk PWM) \\
Electric Current & $50 \mathrm{~mA}$ \\
Flash Memory & $32 \mathrm{~KB}$ \\
Bootloader & SRAM 2 KB \\
EEPROM & $1 \mathrm{~KB}$ \\
Sumber: (Saputri et al., 2014) &
\end{tabular}

Data hasil penelitian yang diperoleh adalah grafik hubungan antara konsentrasi larutan gula terhadap tegangan keluaran. Hasil penelitian tersebut digunakan untuk mencari korelasi linear antara konsentrasi gula terhadap tegangan. Ketika tegangan keluaran dari sampel nira tebu diketahui maka konsentrasinya dapat ditentukan berdasarkan kurva kalibrasi yang diperoleh sebelumnya. Berikut ini merupakan kurva kalibrasi yang digunakan.

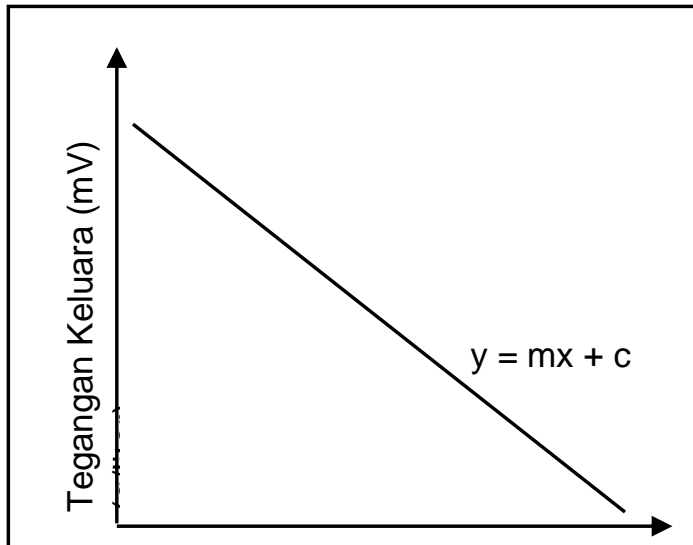

Konsentrasi (gram/liter)

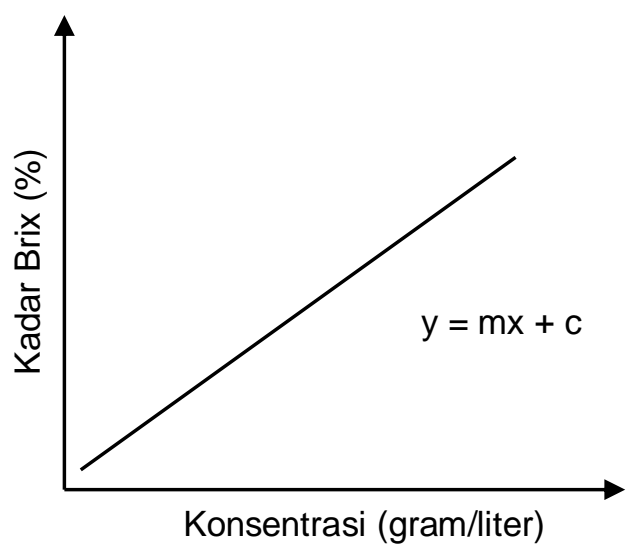

(b)

Gambar 2. Grafik Hubungan antara: a. Konsentrasi terhadap Tegangan Keluaran; b. Konsentrasi terhadap Kadar Brix

Dari kurva kalibrasi yang diperoleh akan diketahui nilai gradien grafik $(\mathrm{m})$ dan konstanta grafik (c). Selanjutnya, kandungan gula pada larutan nira tebu dapat diketahui dengan memasukkan nilai yang telah diperoleh sebelumnya pada persamaan di bawah ini.

$$
x=\frac{y-c}{m}
$$

Keterangan:

$\mathrm{x}=$ konsentrasi nira tebu (gram/liter)

$\mathrm{c}=$ konstanta

$\mathrm{y}=$ tegangan keluaran $(\mathrm{mV})$ atau kadar Brix (\%)

$\mathrm{m}=$ gradien grafik

\section{HASIL DAN PEMBAHASAN}

Hasil pengujian alat ukur kandungan gula menggunakan fotodetektor disajikan pada Tabel 2. 
Tabel 2. Hasil Pengujian pada Kendali Warna dan Intensitas RGB Bright LED Menggunakan Software LabVIEW

\begin{tabular}{ccccc}
\hline \multirow{2}{*}{ No } & \multicolumn{3}{c}{ Bit } & Keadaan RGB \\
\cline { 2 - 4 } & Merah & Hijau & Biru & bright LED \\
\hline 1 & 0 & 0 & 0 & LED mati \\
2 & 150 & 0 & 0 & merah-redup \\
3 & 255 & 0 & 0 & merah-terang \\
4 & 0 & 150 & 0 & hijau-redup \\
5 & 0 & 255 & 0 & hijau-terang \\
6 & 0 & 0 & 150 & biru-redup \\
7 & 0 & 0 & 255 & biru-terang \\
8 & 255 & 255 & 255 & putih-terang \\
\hline
\end{tabular}

Ketiga warna dasar dari RGB komponen warna penyusun dan bright LED dapat dikendalikan dengan menghasilkan keluaran analog berupa laptop untuk keadaan hidup, mati, dan intensitasnya. Pengendalian tersebut dilakukan dengan memanfaatkan sistem bit. Semakin tinggi bit yang digunakan maka RGB bright LED akan menyala lebih terang untuk keadaan warna-warna dasar. Pemberian kombinasi warnawarna dari RGB bright LED sampai beberapa bit akan menghasilkan warnawarna sekunder selain tiga warna dasar tersebut. Pengendalian RGB bright LED tersebut menggunakan masukan serial berupa besaran bit dari masing-masing intensitas sinar RGB bright LED.

Pembacaan tegangan keluaran rangkaian transimpedansi menggunakan masukan analog berupa besaran intensitas sinar yang mengenai sensor fotodioda BPW 34 dan menghasilkan keluaran serial berupa tegangan keluaran dari rangkaian transimpedansi. Alat yang telah dibuat digunakan untuk meneliti kandungan gula pada objek penelitian. Dari penelitian diperoleh kurva kalibrasi sebagai berikut.

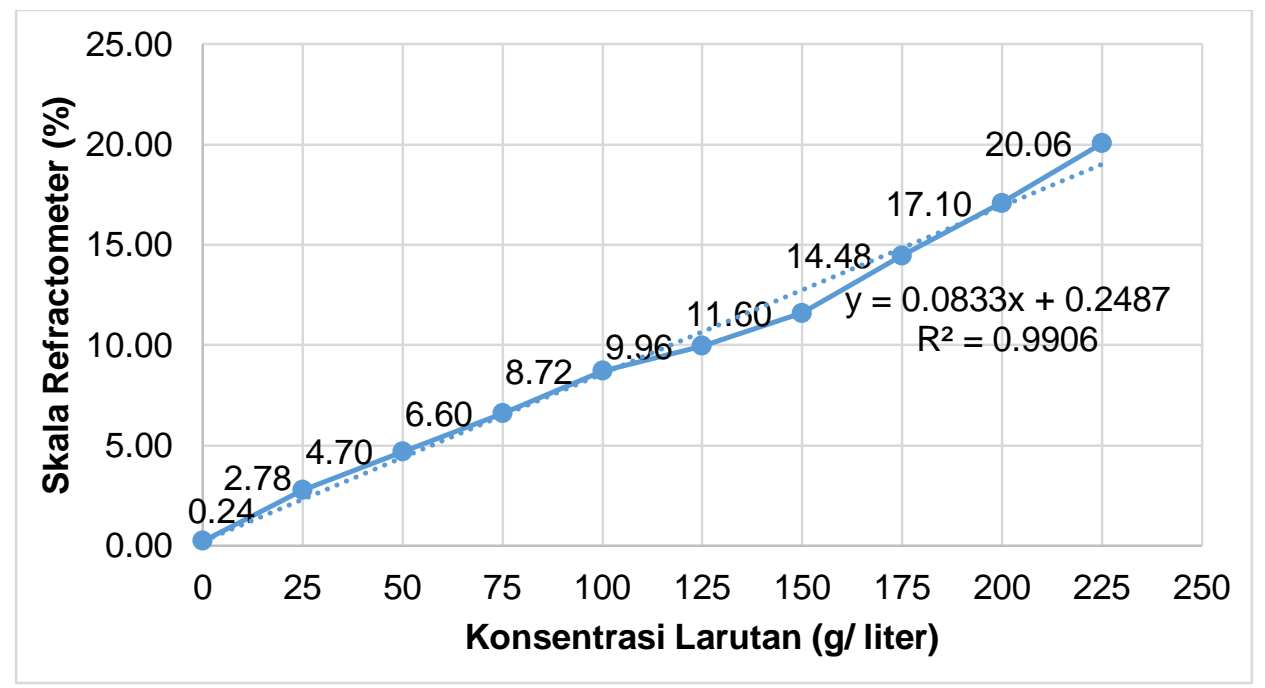

Gambar 3. Grafik Hubungan antara Konsentrasi Larutan Gula terhadap Kadar Brix Refraktometer Digital (Misto et al., 2019)

Berdasarkan Gambar 3 diketahui bahwa kadar Brix akan naik seiring dengan kenaikan konsentrasi larutan gula. Pada refraktometer digital, sinar merambat melewati prisma dengan indeks bias besar menuju sampel dengan indeks bias yang lebih kecil. Sesuai dengan peristiwa refraksi, ketika sinar 
melewati medium yang lebih rapat menuju medium yang renggang maka cahaya akan dibiaskan menjauhi garis normal. kadar Brix diperoleh dari hasil perbandingan antara daerah terang dan gelap dari sensor CMOS atau CCD yang menangkap sinar hasil refraksi. Karena kemampuannya untuk berubah warna sinar maka pada penelitian ini digunakan dua spektrum warna yaitu spektrum warna kuning dan spektrum warna ungu. Adapun pengaturan bit yang diberikan adalah sebagai berikut.

Tabel 3. Hasil Pengujian Kendali RGB Bright LED Berdasarkan Besar bit R-G-B

\begin{tabular}{ccccc}
\hline & \multicolumn{3}{c}{ Besar Bit } & Keadaan RGB \\
\cline { 2 - 4 } No & $\begin{array}{cccc}\text { Merah } \\
\text { Hijau }\end{array}$ & $\begin{array}{c}\text { Biru } \\
\text { B }\end{array}$ & $\begin{array}{c}\text { Bright LED } \\
(\mathrm{B})\end{array}$ \\
\hline 1 & 0 & 0 & 0 & LED mati \\
2 & 255 & 0 & 255 & kuning-terang \\
3 & 150 & 150 & 0 & ungu-terang \\
4 & 255 & 255 & 255 & putih-terang \\
\hline
\end{tabular}

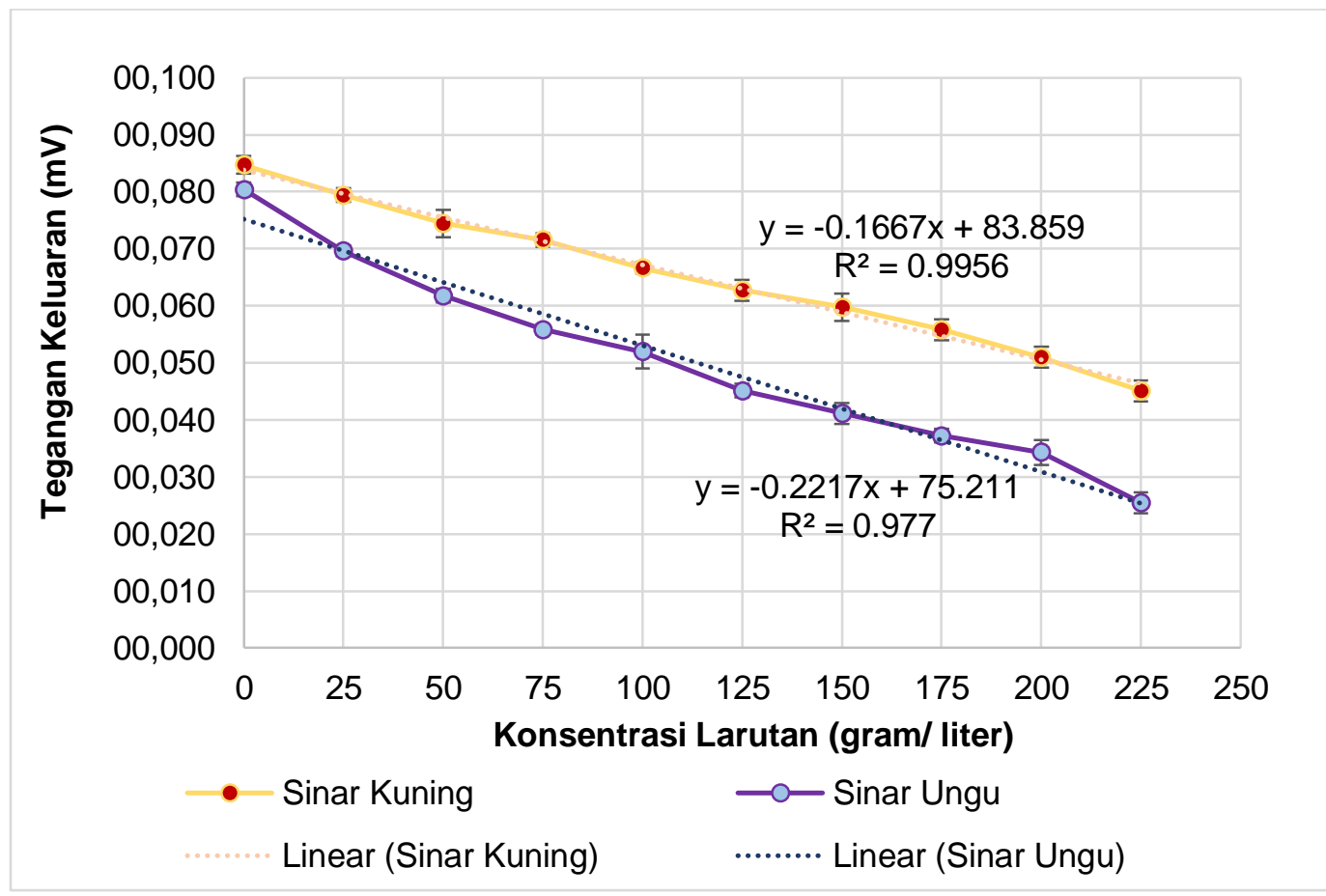

Gambar 4. Grafik Hubungan antara Konsentrasi Larutan Gula terhadap Tegangan Keluaran Rangkaian Transimpedansi

Sedangkan, Gambar 4 Hasil perhitungan data menunjukkan bahwa tegangan keluaran menunjukkan bahwa sinar kuning mampu menurun seiring dengan kenaikan memberikan perubahan tegangan konsentrasi larutan gula. Hal ini keluaran yang lebih besar dibandingkan kemungkinan disebabkan karena adanya sinar ungu untuk setiap variasi proses penyerapan sinar oleh bahan konsentrasi larutan gula sehingga pada terlarut sehingga semakin tinggi pengukuran menggunakan sampel nira konsentrasi larutan gula maka semakin tebu hanya sinar kuning dari RGB bright berkurang intensitas sinar RGB bright LED yang digunakan. Berikut ini hasil LED yang diteruskan. penelitian pada sampel nira tebu. 
Tabel 4. Hasil Pengukuran Kandungan Gula pada Nira Tebu Menggunakan Refraktometer Digital dan Fotodetektor

\begin{tabular}{cccc}
\hline Tebu & Bagian & $\begin{array}{c}\text { Kadar Brix } \\
(\%)\end{array}$ & $\begin{array}{c}\text { Vo } \\
(\mathrm{mV})\end{array}$ \\
\hline \multirow{4}{*}{ A } & Atas & $13,26 \pm 0,04$ & $41,5 \pm 0,5$ \\
& Tengah & $15,76 \pm 0,02$ & $35,8 \pm 0,5$ \\
& Bawah & $17,64 \pm 0,02$ & $32,8 \pm 0,5$ \\
\hline \multirow{4}{*}{ B } & Atas & $13,76 \pm 0,02$ & $40,8 \pm 0,2$ \\
& Tengah & $15,36 \pm 0,02$ & $37,6 \pm 0,2$ \\
& Bawah & $16,70 \pm 0,04$ & $34,5 \pm 0,8$ \\
\hline \multirow{4}{*}{ C } & Atas & $14,58 \pm 0,02$ & $38,3 \pm 0,3$ \\
& Tengah & $15,92 \pm 0,02$ & $35,5 \pm 0,7$ \\
& Bawah & $17,46 \pm 0,02$ & $32,2 \pm 0,5$ \\
\hline \multirow{4}{*}{ D } & Atas & $13,84 \pm 0,02$ & $36,3 \pm 1,2$ \\
& Tengah & $15,56 \pm 0,02$ & $37,1 \pm 0,4$ \\
& Bawah & $17,54 \pm 0,02$ & $32,3 \pm 0,4$ \\
\hline
\end{tabular}

Selanjutnya, kadar Brix (\%) serta berdasarkan kurva kalibrasi yang telah tegangan keluaran rangkaian diperoleh sebelumnya sehingga diperoleh transimpedansi $(\mathrm{mV})$ dikonversi menjadi persamaan sebagai berikut. konsentrasi nira tebu (gram/liter)

Tabel 5. Persamaan Linear Kurva Kalibrasi

\begin{tabular}{cc}
\hline Persamaan Linear & Alat yang Digunakan \\
\hline$y=0,0833 x+0,2487$ & Refraktometer digital \\
$y=-0,1667 x+83,859$ & Fotodetektor \\
\hline
\end{tabular}

Hasil konversi berupa kandungan gula dapat dilihat pada Tabel 6 .

Tabel 6. Hasil Konversi

\begin{tabular}{|c|c|c|c|c|}
\hline \multirow[b]{2}{*}{ Tebu } & \multirow[b]{2}{*}{ Bagian } & \multicolumn{2}{|c|}{ Konsentrasi Berdasarkan } & \multirow{2}{*}{$\begin{array}{c}\text { Selisih } \\
\text { (gram/liter) }\end{array}$} \\
\hline & & $\begin{array}{l}\text { Refraktometer Digital } \\
\text { (gram/liter) }\end{array}$ & $\begin{array}{c}\begin{array}{c}\text { Fotodetektor } \\
\text { (gram/liter) }\end{array} \\
\end{array}$ & \\
\hline \multirow{3}{*}{ A } & Atas & $156,2 \pm 0,5$ & $130,8 \pm 2,5$ & 25,4 \\
\hline & Tengah & $186,2 \pm 0,3$ & $160,5 \pm 2,8$ & 25,7 \\
\hline & Bawah & $208,8 \pm 0,3$ & $175,7 \pm 2,8$ & 33,1 \\
\hline \multirow{3}{*}{ B } & Atas & $162,2 \pm 0,3$ & $134,8 \pm 1,2$ & 27,4 \\
\hline & Tengah & $181,4 \pm 0,3$ & $151,2 \pm 1,3$ & 30,2 \\
\hline & Bawah & $197,5 \pm 0,5$ & $166,9 \pm 3,9$ & 30,6 \\
\hline \multirow{3}{*}{ C } & Atas & $172,0 \pm 0,2$ & $147,3 \pm 1,8$ & 24,7 \\
\hline & Tengah & $188,1 \pm 0,2$ & $161,7 \pm 3,5$ & 26,4 \\
\hline & Bawah & $206,6 \pm 0,3$ & $178,6 \pm 2,5$ & 28,0 \\
\hline \multirow{3}{*}{$\mathrm{D}$} & Atas & $163,2 \pm 0,3$ & $157,9 \pm 6,2$ & 5,3 \\
\hline & Tengah & $183,8 \pm 0,3$ & $153,7 \pm 1,9$ & 30,1 \\
\hline & Bawah & $207,6 \pm 0,3$ & $178,2 \pm 1,8$ & 29,4 \\
\hline
\end{tabular}

Tabel 6 menunjukkan bahwa masih adanya perbedaan nilai hasil pengukuran konsentrasi berdasarkan refraktometer digital terhadap fotodetektor. Perbedaan tersebut dipengaruhi oleh keterbatasan alat dalam mengonversi besaran sinar setelah melalui objek uji menjadi besaran listrik oleh unit pengolah sinyal. Selain itu, perbedaan yang dihasilkan dipengaruhi oleh adanya perbedaan objek pengujian, yaitu larutan gula dan nira tebu yang 
selanjutnya akan berpengaruh pada kurva kalibrasi yang dihasilkan. Jika pada objek larutan gula, material yang terlarut hanya gula saja maka pada nira tebu material terlarutnya adalah sesuai dengan Tabel 7.

Tabel 7. Hasil Analisis Kandungan Nira Tebu

\begin{tabular}{|c|c|c|c|c|c|c|}
\hline \multirow{2}{*}{ Parameter } & \multicolumn{2}{|c|}{$\begin{array}{l}\text { Nira Tebu pH } 4.5 \\
( \pm 0.1)\end{array}$} & \multicolumn{2}{|c|}{$\begin{array}{c}\text { Nira Tebu pH } 5.0 \\
( \pm 0.1)\end{array}$} & \multicolumn{2}{|c|}{$\begin{array}{l}\text { Nira Tebu pH } 5.5 \\
( \pm 0.1)\end{array}$} \\
\hline & $\begin{array}{l}\text { Hasil } \\
\text { Analisis }\end{array}$ & Pustaka & $\begin{array}{l}\text { Hasil } \\
\text { Analisis }\end{array}$ & Pustaka & $\begin{array}{l}\text { Hasil } \\
\text { Analisis }\end{array}$ & Pustaka \\
\hline Kadar Air (\%) & 80,19 & - & 80,26 & - & 80,38 & - \\
\hline Kadar Sukrosa & 15,05 & 15,30 & 16,98 & 17,26 & 18,08 & 18,25 \\
\hline Kadar Gula Redu & 1,59 & 1,23 & 0,98 & 0,69 & 0,54 & 0,57 \\
\hline Kadar Abu (\%) & 0,35 & - & 0,41 & - & 0,45 & - \\
\hline
\end{tabular}

Sumber: (Erwinda dan Wahono, 2014)

Namun, berdasarkan Tabel 6 diketahui tren data hasil pengukuran baik dari refraktometer digital maupun fotodetektor menunjukkan bahwa bagian bawah tebu memiliki konsentrasi yang lebih tinggi dibandingkan ruas tengah dan atas. Hal tersebut disebabkan oleh proses terbentuknya rendemen gula di dalam batang tebu berjalan dari ruas ke ruas yang tingkat kemasakannya tergantung pada umur ruas. Ruas bawah (lebih tua) lebih banyak kandungan gulanya jika dibandingkan dengan ruas di atasnya (lebih muda), demikian seterusnya sampai ruas bagian pucuk (Hebrianto, 2012).

\section{SIMPULAN}

Berdasarkan penelitian yang telah dilakukan, diperoleh kesimpulan yaitu sinar kuning dari RGB bright LED memiliki kemampuan yang lebih baik dibandingkan sinar ungu dalam membedakan konsentrasi larutan gula. Hal tersebut dibuktikan dengan selisih tegangan keluaran rangkaian transimpedansi yang besar untuk setiap perubahan konsentrasi larutan gula sehingga pengukuran pada nira tebu selanjutnya menggunakan sinar kuning dari RGB bright LED. Hasil pengukuran kadar gula pada nira tebu yang diperoleh dari penggunaan fotodetektor memiliki nilai yang berbeda jika dibandingkan dengan refraktometer digital. Penelitian lebih lanjut diharapkan mampu memperkecil selisih hasil pengukuran dari dua alat tersebut.

\section{DAFTAR PUSTAKA}

1. Aini, Fina Nurul, Samian, dan Moh. Yasin. 2013. Deteksi Kadar Glukosa dalam Air Destilasi Berbasis Sensor Pergeseran Menggunakan Fiber Coupler. Jurnal Fisika dan Terapannya. 1 (1): 1-7. ISBN: 9772337-300009.

2. Banzi, Massimo. 2011. Getting Started with Arduino. 2nd Editions. O'reilly.

3. Binu, S., V.P. Mahadevan Pillai, V. Pradeepkumar, B.B. Padhy, C.S. Joseph, dan N. Chandrasekaran. 2009. Fibre Optic Glucose Sensor. Materials Science and Engineering: C. Elsevier. 29 (1): 183-186.

https://doi.org/10.1016/j.msec.2008.06.00 7.

4. Erwinda, Maya Dwi dan Wahono Hadi Susanto. 2014. Pengaruh pH Nira Tebu (Saccharum Officinarum) dan Konsentrasi Penambahan Kapur terhadap Kualitas Gula Merah. Jurnal Pangan dan Agroindustri. 2 (3): 54-64. ISSN: 2354-7936.

5. Fajarini, Kanti. 2011. Rancang Bangun Sistem Pengukuran Kadar Gula Menggunakan Serat Optik Plastik. Surabaya: Institut Teknologi Sepuluh November.

6. Hebrianto. 2012. Proses Pengubahan Nira (Massecuite Juice) Menjadi Kristal Gula di PT. PG Gorontalo Unit Tolangohula Desa Lakeya Kecamatan Tolangohula Kabupaten Gorontalo. Gorontalo: Universitas Negeri Gorontalo.

7. Misto, Tri Mulyono, Bowo Eko Cahyono, dan T. Zain. 2019. Determining Sugar Content in Sugarcane Plants Using LED Spectrophotometer. AIP Conference Proceedings, 2202:020125-1-020125-6. 
https://doi.org/10.1063/1.5141738.

8. Pratama, Anggi, Darjat, dan Iwan Setiawan. 2011. Aplikasi LabVIEW sebagai Pengukur Kadar Vitamin C dalam Larutan Menggunakan Metode Titrasi lodimetri. Semarang: Universitas Diponegoro.

9. Priambodo, lanuar Teguh. 2013. Kontruksi dan Uji Akurasi Alat Otomatisasi Kran Wudhu Dengan Filtrasi 1,33 Liter Menggunakan ATmega8. Jember: Universitas Jember.

10. Saputri, Zaratul Nisa, Mochammad Rif'an, dan Nurussa'adah. 2014. Aplikasi Pengenalan Suara sebagai Pengendali Peralatan Listrik Berbasis Arduino UNO. Malang: Universitas Brawijaya.
Menggunakan Deret Led dan Metode Jaringan Syaraf Tiruan. Surabaya: Institut Teknologi Sepuluh Nopember.

12. Waluyo, Tomi Budi, dan Agus Suheri. 2009. Penggunaan Serat Optik Ragam Tunggal untuk Transmisi Data Pengukuran. Jurnal Fisika Himpunan Fisika Indonesia. 9 (1): 20-28. ISSN: 0854-3046.

13. Zain, Alex Taufiqurrohman, Cahyaning Nur Karimah, Anni Nuraisyah, dan Misto. 2020. Pengujian Sensor Fotodetektor sebagai Alat Ukur Kadar Gula Pada Larutan Gula. Jurnal TAMBORA. 4 (1): 39-45.

https://doi.org/10.36761/jt.v4i1.570. 